\title{
Ensayo
}

\section{La comunicación se genera en el diálogo de la cultura: reflexiones sobre el concepto de audiencia en el pensamiento de Roncallo-Dow}

\section{Manuel Ignacio González Bernal ${ }^{1}$}

DOI: $10.5294 /$ pacla.2020.23.s.4

Para citar este ensayo / to reference this essay / para citar este ensaio González Bernal, M. I. (2020). La comunicación se genera en el diálogo de la cultura. Reflexiones sobre el concepto de audiencia en el pensamiento de Sergio Roncallo-Dow. Palabra Clave, 23(supl.), e23s4. https://doi.org/10.5294/pacla.2020.23.s.4

\section{Resumen}

El presente ensayo recoge varios de los planteamientos de Sergio Roncallo-Dow, Profesor de la Facultad de Comunicación de la Universidad de La Sabana y Editor de la Revista Palabra Clave, sobre la comunicación mediada y sobre el concepto de audiencia. En específico, el texto retoma la ontología de la audiencia, publicada en el libro Estudiar las audiencias: tradiciones y perspectivas, reflexión en la que el autor transitó por cuestiones relacionadas con diferentes visiones sobre el sujeto, el problema de la codificación y la recodificación de la realidad, el lenguaje y la interpretación. Frente a las dicotomías planteadas por las tradiciones dominantes en los estudios de audiencias, la propuesta de Roncallo es desarrollar nuevas o renovadas formas de acceder al conocimiento de la audiencia, en ampliar los marcos teóricos y metodológicos, para así desarrollar otras preguntas, con enfoques diferentes, que, acompañadas de métodos creativos e integradores, permitieran construir miradas más complejas y profundas sobre el público

1 https://orcid.org/0000-0002-8833-4050.Universidad de La Sabana, Colombia. manuel.gonzalez@unisabana.edu.co 
de los medios de comunicación. Para Sergio, estudiar las audiencias desde su unidad constitutiva, es decir desde las personas que la conforman, equivale a emprender un ejercicio hermenéutico sobre sus acciones y contextos. Esto implica analizar, desde diversas aristas, las formas de subjetividad implícitas en la vida personal y social de los sujetos.

\section{Palabras clave}

Audiencia; medios; ontología; cultura; comunicación. 


\section{Introducción}

"Para hablar de audiencias, hay que leer Fedro, es la primera referencia que se conoce de ese tema”, me recomendó Sergio. Era el año 2012 y yo estaba empezando mi doctorado en comunicación. Desde el inicio de este proceso, Sergio se convirtió en una especie de director de tesis ad hoc. Frecuentemente conseguía información sobre mi tema de investigación, me enviaba artículos e, incluso, una vez descargó en mi computador personal cerca de dos mil libros digitales que había conseguido durante muchos años de vida académica.

Entre los años 2013 y 2014 compartimos muchas horas de trabajo en una sala de investigación que nuestra Facultad de Comunicación tenía en el segundo piso de la Biblioteca Octavio Arizmendi Posada, de la Universidad de La Sabana. Era un espacio ideal para "ñoñar", como él solía decir, porque era tranquilo, cómodo y generaba un ambiente intelectual acogedor. Lo mejor era que un piso más abajo teníamos una cafetería pequeña en donde nos surtían de bebidas para las largas mañanas de trabajo, porque en las tardes, él no solía quedarse en el campus.

Fue en ese espacio y en ese tiempo en donde conocí el talante académico de Sergio y en donde descubrí la que para mí sería su principal característica intelectual: la generosidad. Siempre que llegaba con una idea nueva, con un autor, con un texto reciente, lo compartía sin reserva y al final decía ... “¡Vivo para dar!” Al principio pensé que era una más de sus frases jocosas; pero, pronto me di cuenta de que era perfectamente cierto, a él lo hacía feliz compartir su saber, su ciencia, su pensamiento. Por eso, fue un gran profesor $y$ un excelente colega.

Un día, en la sala de la biblioteca, me contó sobre Fedro, el diálogo de Platón. Yo estaba tratando de darle foco a mi tesis. Sabía que quería hacer investigación de audiencias, pero no tenía claro por dónde empezar. Mi visión era ciertamente instrumental, me preocupaba especialmente por los indicadores de consumo de medios, especialmente de televisión, que sentía cortos para la transformación que se estaba dando debido a la acelerada digitalización de los medios y de la sociedad. Ese día hablamos del diálogo, me mostró el apartado específico en donde se abordaba la noción e incluso me enseñó a citar textos clásicos con el sistema alfanumérico tradicional. 
Años después, retomamos esa conversación en Estudiar las audiencias: Tradiciones y perspectivas (González Bernal et al., 2018), un libro que publicamos junto a nuestro amigo y colega Germán Arango. En el primer capítulo nos aventuramos a proponer una deontología del concepto y en ella incluimos el siguiente apartado:

La consideración de la audiencia como parte de procesos sociales también constituyó parte del pensamiento clásico. Una de las primeras aproximaciones al concepto se encuentra en Fedro, el conocido diálogo platónico, en el cual Sócrates habla con Fedro sobre diferentes temas, dentro de los que destacan el amor y la retórica. Es precisamente disertando sobre ésta última cuando Sócrates le dice a Fedro: "Es claro, pues, que Trasímaco y cualquier otro que enseñe con seriedad el arte retórico, describirá en primer lugar y con toda exactitud el alma, y hará ver en ello si es por naturaleza una e idéntica 0, como pasa con la forma del cuerpo, si es también de muchos aspectos. A esto es a lo que llamamos mostrar la naturaleza. (...) En segundo lugar, y conforme a su naturaleza, a través de qué actúa y sobre qué, y qué es lo que padece y por efecto de quién". (Platón, Fedro. 271a). El diálogo continua con otra intervención de Sócrates, quien menciona: "En tercer lugar, y después de haber establecido los géneros de discursos y de almas y sus pasiones, adaptando cada uno a cada una, y enseñando qué alma es la que se deja, necesariamente, persuadir por ciertos discursos y a causa de qué, y por qué a otra le pasa todo lo contrario" (...) Verdaderamente, amigo, que de otro modo no se habría pronunciado ni escrito, según las reglas del arte, ningún ejercicio de escuela, ni ningún discurso, ni ninguna cosa por el estilo. Pero aquellos de los que ahora escriben sobre el arte de las palabras, y de los que tú has oído, son astutos y disimulan, aunque saben, perfectamente, cosas del alma. Pero, hasta que no hablen y escriban de esa manera, no les admitiremos que escriben con arte". (Platón, Fedro. 271b) (González Bernal et al, 2018, p. 32)

En este texto se aprecia una temprana reflexión sobre la variada naturaleza de los públicos y la necesidad de adecuar a ellos los discursos que tienen por objeto la persuasión. En el diálogo, Sócrates hace un llamado a tener presente al sujeto a quien se dirige la comunicación, a conocerle. Así, el texto plantea que la belleza y la perfección en la posesión del arte retórico radican, en buena medida, en actuar de cara a un auditorio identificado, conocido, que por su naturaleza, su alma, marca la pauta para la actuación del orador (González Bernal et al., 2018, p. 32). 
El diálogo, además, pone de manifiesto que la comunicación se concreta y toma sentido en la audiencia, idea que fue reivindicada por Sergio a lo largo de su carrera. Para él, la comunicación no se reduce a los medios o a los mensajes que estos transmiten; por este motivo, afirmó que el estudio de las audiencias, en la actualidad, cobra una importancia capital dentro de cualquier abordaje serio sobre la comunicación.

Pero, ¿qué se estudia sobre la audiencia y por qué vale la pena hacerlo?, ¿cuál es su origen?, ¿cuál es su función dentro del entramado comunicativo? Una vez involucrado con el tema de las audiencias, Sergio no tardó en proponer una ontología del concepto, reflexión en la que transitó por cuestiones relacionadas con diferentes visiones sobre el sujeto, el problema de la codificación y la recodificación de la realidad, el lenguaje y la interpretación (González Bernal et al., 2018).

Esta ontología de la audiencia, que será la base de este ensayo, significó para quienes trabajamos con él y para sus estudiantes, una luz que permitió hacer lecturas críticas, con sentido, de diversas tradiciones teóricas provenientes del campo de la comunicación. A través de los planteamientos allí desarrollados, resulta más sencillo decantar una posición intelectual sobre la audiencia como objeto de estudio y establecer que el sentido de investigarla está en humanizar el proceso de comunicación, pues al ubicar en el centro de la reflexión al sujeto, culturalmente situado y permanentemente productor de significado, recobramos su sentido mismo.

\section{Poniendo las ideas en orden: análisis de las principales concepciones sobre la audiencia}

En Sobre la construcción ontológica del concepto de audiencia, Huertas (2006, p. 30) menciona que 80 años después de haber sido publicada Propaganda Techniques in the World War, de Harold Lasswell (considerada la primera pieza de la corriente del Mass Communication Research), el ámbito de los medios dispone de una amplia y rigurosa bibliografía científica, pero, a pesar de ello, sigue siendo vigente la antigua pregunta de si es posible conocer la audiencia. 
En la ontología del concepto (González Bernal et al., 2018), Sergio respondería sí a esta pregunta y, además, diría que no solo es posible, sino que es necesario. En un escenario mediático cambiante, sujeto a veloces transformaciones provenientes de la digitalización y su impacto en la producción, distribución y consumo de contenidos, esta pregunta sigue vigente y es relevante porque mantiene el foco en la persona, que es principio y fin de la comunicación.

De acuerdo con él, en solo una década, se presentó una de las transformaciones más profundas dentro de las industrias y los mercados de la comunicación, debido al influjo de las tecnologías digitales, lo cual terminó por afectar de manera trascendental los hábitos de las audiencias, sus preferencias de contenido y sus diversas formas de significar la realidad desde su consumo mediático.

Sin embargo, para Sergio, los estudios clásicos y contemporáneos sobre las audiencias no han logrado desentrañar toda esta complejidad y, de manera operativa, han caído en simplificaciones, como la uniformidad de la masa o la hiperfragmentación, que termina en la personalización de la comunicación mediada. Para él, los dos extremos son falaces e impiden comprender en su plenitud la dinámica de la comunicación en la sociedad.

El argumento es sencillo: en cualquier concepción de la audiencia está implícita una visión de persona. La naturaleza de esta visión terminará por fortalecer o empobrecer la mirada sobre la comunicación y sobre lo social. Por lo anterior, resulta necesario desentrañar qué tipo de persona está caracterizada dentro de los discursos de audiencias. Al respecto Sergio identificó dos extremos opuestos, que dan origen a posiciones encontradas sobre el fenómeno. Para referirse a ellos los llamó lugares comunes.

\section{Uniformidad y homogeneidad: la audiencia como masa}

El primer lugar común es el de audiencia como masa, desarrollado a partir de los conceptos provenientes de la teoría de la sociedad de masas, imperantes durante la primera mitad del siglo XX. Esta perspectiva interpreta la audiencia como homogénea y uniforme y conlleva a caracterizar a sus 
miembros como manipulables, a través de mensajes que adoptan la forma de propaganda (Wolf, 1987).

$\mathrm{Al}$ respecto, Ortega y Gasset, en el prólogo para franceses de La rebelión de las masas, publicado en 1937, sintetizó su propia mirada sobre ese individuo a quien llamó "el hombre masa":

Triunfa hoy sobre toda el área continental una forma de homogeneidad que amenaza consumir por completo aquel tesoro. Dondequiera ha surgido el hombre-masa de que este volumen se ocupa, un tipo de hombre hecho de prisa, montado nada más que sobre unas cuantas y pobres abstracciones y que, por lo mismo, es idéntico de un cabo de Europa al otro. A él se debe el triste aspecto de asfixiante monotonía que va tomando la vida en todo el continente. Este hombre-masa es el hombre previamente vaciado de su propia historia, sin entrañas de pasado y, por lo mismo, dócil a todas las disciplinas llamadas «internacionales». Más que un hombre, es sólo un caparazón de hombre constituido por meros .carece de un dentro, de una intimidad suya, inexorable e inalienable, de un yo que no se pueda revocar. De aquí que esté siempre en disponibilidad para fingir ser cualquier cosa. Tiene sólo apetitos, cree que tiene sólo derechos y no cree que tiene obligaciones: es el hombre sin la nobleza que obliga -sine nobilitate-, snob. (Ortega y Gasset, 2009, p. 49)

Este "hombre masa", descrito con vehemencia por el pensador español, no era otro distinto a aquel que conformaba la audiencia que atendía los medios de comunicación. De ahí, las primeras miradas de la audiencia como masa, con un sentido peyorativo y empobrecedor de las calidades humanas en su interacción con el contenido de los medios de comunicación, que también empezaron a recibir el apelativo de masivos, en consideración tanto al perfil como a la cantidad de su público.

Por su parte, Herbert Blumer, discípulo de Park, en The mass, the public and public opinion (1939) sienta las bases para explicar la audiencia, a modo de masa, como una nueva forma de colectividad que era posible gracias a las características de la sociedad moderna. Según este teórico, la idea de masa abarcó varias de las características de las audiencias del cine y la radio que no estaban comprendidas dentro de otras formaciones sociales, como los grupos, las muchedumbres y los públicos. ${ }^{2}$

2 McQuail (2000, p. 78-79), basado en Blumer (1939), menciona que, en los grupos, todos los miembros se conocen entre sí, son conscientes de su pertenencia al grupo, comparten los mismos valores, tienen determinada estructura 
Para McQuail (2000), esta nueva audiencia, la masiva, solía ser más numerosa, estaba geográficamente dispersa, era demográficamente heterogénea, se conformaba por desconocidos, carecía de identidad y consciencia propias y, por lo anterior, no era capaz de organizarse para actuar y conseguir objetivos. No se movía por sí misma, sino que más bien se actuaba sobre ella a través de la manipulación y en lo único en lo que coincidían sus miembros era en la adopción de un objeto de interés que las convocaba y en la percepción de quiénes estaban interesados en manipularlas. Huertas (2006) coincide con esta caracterización al afirmar que la audiencia era considerada como un grupo homogéneo, pasivo, desestructurado (rechazando así, por ejemplo, la estructura jerárquica derivada del sistema de clases sociales) y carente de identidad colectiva.

Para Sergio, la pregunta sobre la audiencia toma importancia a partir de esta idea de masa, pues en ella convergen muchos de los elementos de la vida cotidiana moderna: el espacio, encarnado en la ciudad; la dinámica de comunicación, materializada en los medios; las lógicas de poder y dominación, convertidas en necesidad de persuasión política y de consumo. Las audiencias, no solo ciudadanos o sujetos, reciben las presiones propias de la vida en la modernidad y conviven con ellas en un nuevo tipo de realidad.

Desde esta perspectiva, una gran presión que enfrenta el ciudadano es la propaganda, desarrollada con la intención de manipular el comportamiento social, político y económico de las audiencias. Cuando se piensa en el hombre masa, como aquel sujeto aislado, vacío de tradición y de comprensión de su presente, es perfectamente lógico considerarlo manipulable y, por lo tanto, hacer cosas (propaganda), para orientar su vida.

de relaciones que permanece estable en el tiempo e interaccionan para lograr algún objetivo. La muchedumbre es mayor, aunque queda confinada dentro de límites observables y en un espacio determinado. Sin embargo, es provisional y raramente vuelve a formarse con la misma composición. Puede poseer un alto grado de identidad y compartir el mismo estado de ánimo, si bien su moral y su composición social carecen normalmente de estructura y orden. Puede actuar, pero sus actos suelen revestir un carácter afectivo y emocional, a menudo irracional. El público suele ser grande y duradero, aunque esté sumamente disperso. Tiende a formarse alrededor de una cuestión o causa de la vida pública y su objetivo principal consiste en postular una opinión, favorecer un interés o lograr cambios políticos. Es un elemento esencial de la democracia, basada en el ideal del discurso racional dentro de un sistema político abierto, a menudo formado por la sección mejor informada de la población. El desarrollo del público es normal en las democracias liberales modernas y se le relaciona con la aparición de la prensa burguesa o de partido. 
Sergio, usando a Baudelaire (2006) y a Benjamin (2006) se refirió al hombre masa como el flaneur, el sujeto urbano de la modernidad. El flaneur, visto como audiencia, evidencia la división generada entre el sujeto y su espacio, que se origina en la ruptura de lenguaje y que termina por impedir la comunicación entre el ciudadano y su polis.

Diría Sergio en Estudiar las audiencias: tradiciones y perspectivas (2018) que el espacio es un problema de comunicación. Una sociedad comunica lo que es a través de los espacios. En este sentido, las ciudades son lugares privilegiados de comunicación. Agregaría que la ciudad moderna genera un lenguaje centrado en el Estado. Un lenguaje de asimetría, no de igualdad y libertad, como sucedía en el ágora de los griegos. Así, la ciudad moderna genera soledad y aislamiento del sujeto, en medio de la multitud, lo que genera un nuevo hombre: vacío, desligado de sus semejantes e incluso de su tradición. El hombre masa, la audiencia (González Bernal et al., 2018, pp. 18-21).

\section{Fragmentación: la audiencia individualizada}

El otro lugar común viene con el desarrollo del siglo XX, la evolución de la tecnología y la mayor comprensión de los fenómenos sociales que, en conjunto, transformaron el concepto de audiencia como masa, en uno opuesto, caracterizado por el carácter activo, la capacidad de selección, la interpretación y la (re)codificación realizada de manera personal. Esta mirada, además, es complementada por conceptos como el de mediación (Martin Barbero, 1987; Orozco, 2003), ampliamente usado por Sergio en su análisis sobre el proceso de comunicación social.

En contraposición a las miradas lineales de estímulos y respuestas, disfrazadas de propaganda y efectos, Sergio encontraba la mirada más positiva de los estudios de la recepción. En ellos, se veía a una audiencia compuesta por sujetos racionales y activos, capaces de decodificar, interpretar y filtrar los significados de los contenidos, de acuerdo con sus circunstancias personales, sociales y con su cotidianidad. No obstante, en este escenario, cada individuo es una audiencia única; por este motivo, resulta pretencioso aspirar a conocerlos y comprenderlos a todos en conjunto. 
Así, la investigación instalada en esta hiperfragmentación, propia de los estudios de la recepción, termina en un lugar común que dificulta una real comprensión de la audiencia, en la medida en que su método natural es el cualitativo, lo cual facilita comprender casos concretos a fondo, pero hace inabarcable al acercamiento total a los consumidores de medios.

De manera complementaria, Sergio propondría que ni uniformidad, ni excesiva individualidad pueden explicar el fenómeno complejo que se produce en la interacción entre medios, contenidos y usuarios, porque es frecuente que un mismo individuo se comporte de diferentes maneras al ser audiencia. Por ejemplo, cuando un sujeto ve en la televisión un juego de su equipo de fútbol, puede adoptar comportamientos colectivos, altamente emocionales e incluso irracionales, propios de las masas; mientras que la misma persona, al sentarse en su computador y desarrollar otros consumos, despliega comportamientos particulares, personaliza el contenido e incluso desarrolla rituales de consumo únicos. ¿En este caso, el receptor a quien nos referimos es el hombre masa o es un individuo receptor?

Frente a esta dicotomía, su propuesta se enfocó en promover nuevas o renovadas formas de acceder al conocimiento de la audiencia y en ampliar los marcos teóricos y metodológicos, para, así, desarrollar nuevas preguntas con enfoques diferentes, que, acompañadas de métodos creativos e integradores, permitieran construir miradas más complejas y profundas sobre el público de los medios de comunicación.

Una de esas formas fue, por ejemplo, el seguir las pistas dejadas por el contenido mediático en los comportamientos, interacciones y usos realizados por las personas. Este tipo de propuesta implicaba estudiar detalladamente el contenido, incluso develando el discurso implícito. Al mismo tiempo, implicaba conocer cuantitativamente el consumo de dicho contenido por parte de los individuos y cualitativamente las formas de apropiación y los rituales de consumo, para finalmente hacer análisis cruzados de la información, que permitieran acercarse, de manera holística, a la generación de sentido y significado, que daba lugar a visiones e imaginarios de sociedad. 
Acercamientos de este tipo se desarrollaron en proyectos de investigación académicos en los que participó Sergio, que, además de su valor metodológico y conceptual, alcanzaron a tener repercusión empresarial (González Bernal et al., 2018), lo que demostró la utilidad de su propuesta intelectual.

\section{El aporte: una ontología basada en el sujeto, el mensaje y el contexto cultural}

Para Sergio, estudiar las audiencias de formas más holísticas e integradoras, con foco en su unidad constitutiva, es decir, en las personas que la conforman, equivale a emprender un ejercicio hermenéutico sobre sus acciones y contextos. Esto implica analizar, desde diversas aristas, las formas de subjetividad implícitas en la vida personal y social de los sujetos.

Cuando se aborda esta subjetividad desde la inmaterialidad de la comunicación mediada, los retos son mayores. Sin embargo, hacerlo resulta importante, pues un proceso de comunicación exitoso, más allá de entregar un mensaje, implica una decodificación, una significación y, por lo tanto, una transformación del sujeto receptor. Esta determinación de la persona tiene que ver con la posibilidad de cada sujeto de leer e interpretar creativamente las formas simbólicas, incluidos los productos mediáticos, y llevar el resultado a su vida cotidiana.

En este sentido, se produce una doble determinación (González Bernal et al., 2018, pp.40-44), pues el consumo mediático determina el acervo cultural de los sujetos consumidores y, a la vez, dicho acervo es la base para el ejercicio hermenéutico propio de la generación del sentido.

En la lógica de Sergio, tan pronto se comprende la naturaleza dinámica y sumativa del proceso de significación, vienen a la mente otros problemas como el uso que las personas hacen de su significación o la autonomía que tienen para significar, pues siempre habrá una intervención en la generación de significados desde el contenido consumido.

Este último problema, un tanto binario, llevaría necesariamente a los reduccionismos mencionados anteriormente: la manipulación o la autode- 
terminación semiótica del individuo. Buscando un escape a un círculo vicioso, Sergio decidió tomar otro camino y propuso una conceptualización diferente del sujeto, del mensaje y del medio, mejor adaptadas a la realidad actual. Para ello, planteó un marco de referencia a través de la revisión de los postulados sobre audiencias provenientes del marxismo y del liberalismo, las dos corrientes principales que dan origen a los discursos dominantes sobre audiencias, $y$, luego, incluyó una alternativa diferente, a la que llamó "revisionista".

\section{Las miradas tradicionales: Ios medios y los sujetos}

En la postura marxista encontró que los medios son instrumentos de poder, los mensajes traen significados prediseñados, la audiencia es homogénea (masa), está dominada y no tiene la posibilidad de producir significados propios. Esta perspectiva, evidentemente, se alimenta de los postulados de los pensadores críticos de la escuela de Frankfurt (Wolf, 1987).

En la postura liberal-pluralista enfatizó en unos medios vistos como instrumento del poder, pero no del Estado, sino del ejercido por diversos actores sociales. Además, una aparente simetría entre medios y audiencias, por ser las dos partes activas en el proceso de comunicación. Esto último implica entender las audiencias como sujetos con capacidad de interpretar y criticar; que incluso, tienen el potencial de convertirse en opinión pública.

La posición revisionista, basada en los planteamientos de David Morley (1992) y John Fiske (1978) recupera el protagonismo del sujeto en el proceso comunicativo y centra el consumo en sus expectativas. Para Fiske, el concepto articulador será el de democracia semiótica, a través del cual pretende construir un sujeto-audiencia con posibilidad de desarrollar un amplio número de lecturas e interpretaciones de los textos mediáticos, motivo por el cual la construcción del significado dependerá mayoritariamente de él y de sus referentes de interpretación, provenientes del contexto cultural.

\section{La propuesta: el sujeto-contexto cultural}

La anterior síntesis deja en evidencia la necesidad de tomar posición conceptual-intelectual al momento de abordar estudios sobre audiencias, debido a las divergentes ideas que se han desarrollado sobre este fenómeno 
dentro de los estudios de la comunicación. Una u otra elección nos llevará por caminos, preguntas y métodos de trabajo variados e incluso excluyentes.

Sergio claramente optó por el camino revisionista, por encontrarlo más natural; pero, también, más interesante, no solo por el reconocimiento de la capacidad decodificadora, interpretadora y recodificadora del sujeto, sino por los elementos extrínsecos que entran a hacer parte de este entramado.

Para él, estos elementos estaban directamente conectados con el concepto de cultura, entendida como un modo de vida, un modo de cotidianeidad (González Bernal et al., 2018, p. 41). En este sentido, el sujeto-audiencia es un sujeto cultural, es decir, tiene un cierto tipo de vida y pertenece a un tipo específico de grupo; por lo tanto, está culturalmente condicionado, no por el poder del Estado, ni de la ideología, sino por su entorno.

Desde esta lógica, el sentido no se construye en el vacío, como de alguna manera plantean las visiones marxistas, sino que los discursos culturales que acompañan al sujeto receptor tienen una amplia y profunda influencia en la generación de significados, en la construcción de sentido y por, supuesto, en el uso de esa significación en la vida diaria de las personas. Morley (1996, p.127 citado por González Bernal et al. 2018, p.41) se refiere a este proceso como los prejuicios, no en el sentido común y negativo del término, sino entendido como ese conjunto de condiciones que determinan la interpretación.

\section{La hermenéutica del mensaje}

Es claro que, desde esta perspectiva, la interpretación está condicionada por el contexto cultural del sujeto, pero el texto mediático mismo tiene una propuesta de significado que viene en él. Así, el proceso de generación de sentido se produce en ese contraste entre nuestros prejuicios culturales y las propuestas del texto. Para Sergio, basado en las ideas de Hegel, este será un proceso permanente; pues, como audiencia, estaremos permanentemente expuestos a los mismos y a nuevos textos mediáticos, que retarán y transformarán paulatinamente las bases de nuestra cultura (González-Bernal, et al., 2018, p. 42) 
Sobre este punto, Sergio nos invita a ser conscientes de que nuestro bagaje cultural, nuestros prejuicios son la principal barrera o el principal condicionamiento que tenemos en el momento de ser interpretes de la realidad y, dentro de ella, de los mensajes de los medios. En este sentido, la pregunta se transforma y pasa a ser żcómo abordar los textos desde su alteridad y no desde una mirada dogmática, ampliamente marcada por condicionantes culturales? La respuesta es obvia: hay que dejar al mensaje hablar, dialogar con nuestra cultura y de allí surgirá la esencia hermenéutica, que consiste en notar que tanto receptor como emisor son sujetos activos en el proceso de comunicación y que para lograr el diálogo es necesario el reconocimiento mutuo. Este reconocimiento mutuo implica reconocer también los prejuicios culturales del codificador y dejarlos aflorar en el mensaje.

De acuerdo con los anteriores planteamientos, los efectos directos y lineales, típicamente expuestos por las primeras aproximaciones a la audiencia, resultan poco convincentes, en la medida en que desconocen la memoria cultural y proponen un sujeto sin tradición, que habita en el vacío: un sujeto acultural. Desde el planteamiento hermenéutico, los sujetos que habitan el mundo interactúan con él y con otros sujetos en un escenario cultural complejo.

Dicho esto, en una etapa de la sociedad, marcada por un acelerado avance tecnológico, que permite la explosión de canales de comunicación, de mensajes y de formas de consumo, con evidentes riesgos como, por citar solo un ejemplo, la manipulación generada a través de la difusión de noticias falsas, vemos que hay algo más allá de las intenciones de los emisores, más allá de satanizar las tecnologías de producción, distribución y consumo. El verdadero peligro está en los referentes de interpretación que impiden el diálogo y que nos llevan acríticamente a rechazar o aceptar propuestas de significado.

Por ejemplo, mientras una noticia falsa para algunos es, a primera vista, ilógica e inverosímil, para otros resulta perfectamente coherente y, por lo tanto, digna de ser compartida con más personas. En sentido contrario, 
una información real, que choca con el contexto cultural de un sujeto decodificador, tiende a ser interpretada como mentira y por extensión como mentiroso a su creador o difusor.

Aceptar las mentiras o rechazar las verdades con tanta facilidad, de manera casi natural, deja en evidencia la poca apertura que las personas demuestran a ese diálogo hermenéutico del que nos habla Sergio. Esta clase de fenómenos, cada vez más presentes en la vida diaria, muestran la necesidad que tiene la sociedad, materializada en la audiencia de los medios de comunicación tradicionales y digitales, de fortalecer sus marcos de interpretación, sin caer en una especie de sordera cultural que impida escuchar lo diferente.

\section{Referencias}

Benjamin, W. (2006). The writer of modern life: Essays on Charles Boudelaire (M. Jennings (ed.)). Harvard University Press.

Blumer, H. (1939). The mass, the public and public opinion. In A. M. Lee (Ed.), New Outlines of the Principles of Sociology. Barnes and Nobel.

Fiske, J., \& Hartley, J. (1978). Reading Television. Taylor \& Francis. https:// doi.org/10.4324/9780203356623

González Bernal, M. I., Roncallo-Dow, S. \& Arango-Forero, G. (2018). Estudiar las audiencias: tradiciones y perspectivas. Universidad de La Sabana. https: //doi.org/10.5294/978-958-12-0482-3

González Bernal, M. I., Roncallo-Dow, S., Uribe-Jongbloed, E., \& ArangoForero, G. (2016). Factores que facilitan la generación de "engagement" con programas de televisión: exploración cualitativa desde la identidad del canal, las características del producto y la valoración de las audiencias. Estudios Sobre El Mensaje Periodistico, 22(2), 995-1017. https://doi.org/10.5209/ESMP.54248 
Huertas, A. (2006). Sobre la construcción ontológica del concepto de audiencia. Fronteiras Estudios Mediáticos, VIII (3), 196-202. http:// revistas.unisinos.br/index.php/fronteiras/article/view/6134

Martin Barbero, J. (1987). De los medios a las mediaciones; comunicación, cultura y heegemonía. Gustavo Gili S.A.

McQuail, D. (2000). Introducción a la teoría de la comunicación de masas (P. Comunicación (ed.); Cuarta). Paidós.

Morley, D. (1992). Television, audiences and cultural studies. Routledge.

Orozco, G. (2003). Los estudios de recepción: de un modo de investigar, a una moda, y de ahí a mucho modos. Intexto, 2(9), 1-13. https:// seer.ufrgs.br/intexto/article/view/3629

Ortega y Gasset, J. (2009). La Rebelión de las Masas. Espasa Calpe, S.A.

Wolf, M. (1987). La investigación de la comunicación de masas: crítica y perspectivas. In Instrumentos Paidós (Issue 2). Paidós. 